\title{
GÖZENE KÖYÜ AĞZINDA “OYUN, MEVSIM, YEMEK VE GIDA” İLE İLGİLİ KÜLTÜREL UNSURLARA AİT SÖZ VARLIĞI
}

\author{
The Vocabulary Of Cultural Elements Related To "Game, Season, Food And Food" In The Mouth Of \\ Gözene Village
}

Dr. Öğr. Üyesi Osman TÜRK

Harran Üniversitesi, Fen Edebiyat Fakültesi, Yeni Türk Dili ABD., Şanluurfa, Türkiye, osmanturkgau@gmail.com

Dr. Fatma KOC

Milli Eğitim Bakanlı̆̆l, Yeni Türk Dili ABD., Adlyaman, Türkiye, fatma_koc_1991@hotmail.com

\begin{tabular}{|c|c|}
\hline & Araștırma Makalesi/Research Article \\
\hline \multirow{2}{*}{ Makale Bilgisi } & $\ddot{\mathbf{O ̈ z}}$ \\
\hline & Gözene köyü Malatya'nın Yeşilyurt ilçesine bağlı bir köydür. Gözene köyünün yer şekillerinden dolayı \\
\hline $\begin{array}{l}\text { Geliş/Received: } \\
06.07 .2021\end{array}$ & $\begin{array}{l}\text { halk, toplu bir şekilde yaşamak zorunda kalmıştır. Köyde yaşayan halkın diğer coğrafî alanlara gitmemesi, } \\
\text { köyde kullanılan ağzın bozulmamasını sağlamıştır. Dolayısıyla insanlar dış etkilerden uzak kaldığı için } \\
\text { geleneklerine ve göreneklerine sadık kalmışlardır. Geçmişten geleceğe aktarılan kültür, saf hâliyle }\end{array}$ \\
\hline $\begin{array}{l}\text { Kabul/Accepted: } \\
30.09 .2021\end{array}$ & $\begin{array}{l}\text { korunmuş ve bu kültürün izleri söz varlığında canlılığını korumuştur. Ağız çalışmalarının araştırılması ve } \\
\text { arşivlenmesi, Türk dilinin yazılı belgeleri olarak dilimizin varlığına ait bir kanıt oluşturur. Dolayısıyla ağız } \\
\text { çalışmalarında özgün sözcüklerin tespit edilmesi aynı zamanda kültür aktarımına da katkı sağlamış olur. } \\
\text { Ağız çalışmaları maddi ve manevi kültür unsurlarımıza ait değerleri ortaya çıkarılması bakımında }\end{array}$ \\
\hline Sayfa/ Page: & önemlidir. Bu bağlamda dilin zenginliği fark edilmesi ve tarihi süreci anlamlandırması ve millete ait kültür \\
\hline $20-27$ & değerlerinin ortaya çıkarılabilmesi için ağız çalışmaları önemlidir. Bu çalışmada Doç. Dr. Özlem Demirel \\
\hline & Dönmez ve Dr. Fatma Koç’un birlikte hazırladıkları "Malatya İli Yeşilyurt İlçesi Gözene Köyü Ağzı" \\
\hline & $\begin{array}{l}\text { kitabından yararlanılmış olup kitabın sözlük bölümü kullanılmıştır. Kitabın sözlük bölümünde geleneklere } \\
\text { ait sözcükler taranmış, tarama yönteminden sonra bu tür sözcüklerin sayısı tespit edilmiştir. Daha sonra }\end{array}$ \\
\hline & tespit edilen sözcükler 3 başlık altında kategorize edilmiştir. Bu sözcükler hakkında açıklamalarda \\
\hline & $\begin{array}{l}\text { bulunulmuş sonuç bolumunde belirlı çıkarımlara ulaşılmıştır. } \\
\text { Anahtar Sözcükler: Gözene Köyü, Ağı, Sözcük, Söz Varlığı, Kültürel Unsurlar. }\end{array}$ \\
\hline
\end{tabular}

ijof.963299

\begin{abstract}
Gözene village is a village in the Yeşilyurt district of Malatya. Due to the landforms of the village of Gözene, the people had to live collectively. The fact that the people living in the village did not go to other geographical areas ensured that the language used was not spoiled. Therefore, people have remained loyal to their traditions and customs as they stay away from external influences. The culture, transferred from the past to the future, has been preserved in its pure form and the traces of this culture have preserved its vitality in the presence of vocabulary. Researching and archiving dialect works will provide evidence of the existence of our language as written documents of the Turkish language. Therefore, identifying original words in dialect studies will also contribute to the transfer of culture. Dialect studies are important in terms of revealing the values of our material and spiritual cultural elements. In this context, dialect studies are important in order to realize the richness of the language, to make sense of the historical process and to reveal the cultural values of the nation. In the study, Assoc. Dr. Özlem Demirel Dönmez and Dr. Fatma Koç the book "Gözene Village of Malatya Province Yeşilyurt District" was used and the dictionary section of the book was used. Words belonging to traditions were scanned in the dictionary section of the book. The number of these words was determined after the scanning method. Later, the detected words were categorized under 7 headings. Explanations were made about these words and certain inferences were reached in the conclusion section.

Key Words: Gözene Village, Dialect, Sözcük, Vocabulary, Cultural Elements.
\end{abstract}

Attf/Citation: TÜRK, O., KOÇ, F. (2021). Gözene Köyü Ağzında “Oyun, Mevsim, Yemek Ve Gıda” İle İlgili Kültürel Unsurlara Ait Söz Varlı̆̆ı, International Journal of Filologia ISSN: 2667-7318 Y11: 4, Sayı: 6, Sayfa: 20-27.

Sorumlu Yazar/Corresponding Author: Dr. Öğr. Üyesi Osman TÜRK

Yazar Katkı Oranı Beyanı/Author Contribution Rate: Araştırmacılar çalışmaya eşit oranda katkı yapmışlardır.

Çatışma Beyanı/Conflict Statement: Makalenin yazar/yazarlanı bu çalışma ile ilgili taraf olabilecek herhangi bir kişi ya da finansal ilişkileri bulunmadığını dolayısıyla herhangi bir çıkar çatışmasının olmadığını beyan ederler. 


\section{Giriş}

Dil duygu ve düşünceleri aktarmada önemli bir unsurdur. Dil, bir toplumun zihin yapısını gösteren, milleti millet yapan, insan ile toplum arasındaki bağı sağlayan en güçlü kültür öğesidir. İnsanların kavram ve nesneleri adlandırmalarının altında yatan pek çok neden bulunmaktadır. Politik sebepler, doğa olayları, coğrafi şartlar, geçim kaynakları, uğraşılan meslekler akla ilk gelen nedenlerdir (Tuğluk, 2021: 154-155). Dil vasıtasıyla kelimelerin değişik coğrafyalarda ve zamanlarda yer değiştirmesi kaçınılmazdır. Bu bağlamda bakıldığında kültürel bağların nesilden nesile aktarımının sağlanabildiğini ve toplum yapısının anlaş1lırlığını kolaylaştıran asıl unsurdur. İnsanların yaşadığı toplum yapısıyla bağlantılı olarak bir yaşayış şekli ve dil yapısı vardır (Türk, 2017: 786). Dil, yaşamın her alanında varlığını gösteren, dilin etkide bulunma gücü yaşamın bütün alanlarına yayılır. Dilin kendine mahsus gereksinimleri ve koşulları ile kendi çevresini ve yönünü belirler (Türk, 2020: 323). Dil, insanlarla iletişimi sağlayan, bir ulusu ulus yapan değerleri geçmişten geleceğe taşıyan, bir ulusu ayakta tutan ve o ulusun varlığını devam ettiren en önemli sosyal unsurdur. Dilin bu özelliği kültürün aktarılmasında en önemli araçtır. Bir ulusa ait olan değerler bütününü dil vasıtasıyla gelecek nesillere aktarılır. Kültür hazinesinde yer alan değerleri tespit etmek için ağız çalışmaları bu bakımdan önemlidir. Mazide yer alan sözcüklerin hangi aşamalardan geçtiğini Türk dil tarihini görebilme adına derlenecek sözcüklerin ağız çalışmaları vasıtasıyla anlaşılması sağlanacaktır. Maddi ve manevi kültüre ait arkaik olarak yer alan sözcüklerin açığa çıkarılması dil çalışmalarına önemli kaynak oluşturacaktır.

Bir dilbilimi olarak "ağız (frn. parler / alm. mundart / ing. language / ita. parlata)" genel anlamda bir dilin veya lehçesinin sınırları içerisinde belli bölge veya topluluklara özgü sözlü anlatım yollarının bütünü olarak açıklanabilir (Gemalmaz, 1989: 3). Aynı dil içinde ses, şekil, söz dizimi ve anlamca farklılıklar gösterebilen, belli yerleşim bölgelerine veya sınıflara özgü olan konuşma dili şeklinde belirtmiştir (TS, 44). Bir dilin bir şive içinde mevcut olan ve söyleyiş farklarına dayanan küçük kollara, bir memleketin çeşitli bölge ve şehirlerinin kelimeleri söyleyiş bakımından birbirinden ayrı olan konuşmalara verilen ad olarak tanımlamaktadır (Ergin, 2013: 10). Bir dilin alanı içinde görülen konuşma biçimlerini, söyleyiş türlerini, kimi durumlarda da toplumsal özellikleri yansıtan kullanımların her biri olarak anlamlandırmaktadır (Vardar, 1998). Bir dilin, lehçeler içinde ses, yapı ve anlam bakımından bazı ayrılıklar içeren halkın konuştuğu değişik biçimi olarak belirtiyor (Topaloğlu, 1989). Dil biliminin bir dil içerisinde birbirlerine göre durumları ve yakınlıkları fark etmeksizin lehçe, şive ve ağızları inceleyen ve bunları özelliklerini belirleyen dalına lehçe bilimi olarak tanımlayabiliriz. Bir lehçenin yapılan çalışmalara daha dar anlamda "ağız bilimi araştırması adının verilmesi daha yerinde tespit olacaktır (Gemalmaz, 1989: 3). Bir dilin veya bir lehçenin daha küçük yerleşim bölgelerinde yazı diline oranla birbirinden az çok ayrılan biçimleri şeklinde ifade eder (Korkmaz, 2010, 12). Genel anlamda yapılan açıklamalara bakıldığında birbirine yakın olmakla beraber, bir toplumun kültür yapısı bakımından da çok önemli olduğu ifade edilmiştir. Bir toplumun dağarcığında yer alan kelimelerin tespiti bakımında ağız çalışmaları önemli yer tutar. Ağızlar canlı dil kaynakları olduğu gibi dil çalışmaları için de önemli bir malzeme oluştururlar. Ağız çalışmalarıyla birlikte kaybolmakta olan değerlerin tekrardan tespit edilmesi, var olan halkın sözlü kültürünü ve canlılığı devam eden kültürel değerlerinin kayıt altına alınması bakımından son derece önemlidir. Son yüzyılda ağız çalışmaları ülkemizde önemli ölçüde mesafe kat etmiştir. Gerek il bazında gerekse daha özel alanları kapsayan ağız çalışmaları yapılmıştır. Bu bağlamda bakıldığında Türkiye'de ağız çalışmaları 19. yüzyıla kadara gider. 1867 yılında Maksimov'un Hüdevandigar ve Karamanlı ağızlar üzerine yazdığ1 "Opıt izslědovanija tyurskich dialektov v Chudavendigarĕ i Karamanii" adlı çalışma başlangıç olarak görülebilir (Gökçe, 2019: 80). Sonraki süreçte ağız çalışmalarıyla ilgili daha çok yabancı araştırmacılar olmakla beraber bu alana ilgi uyandırmıştır. Türk Dil Kurumunun desteğiyle de 
Anadolu ağızlarına olan alaka giderek artmaya başlamıştır. Bu araştırmacılar arasında A. Caferoğlu öncü olarak gösterilebilir. Caferoğlu Anadolu'nun çeşitli bölgelerinden derlemeler yaparak oluşturduğu dokuz ciltlik derleme çalışması Anadolu ağızları üzerinde yapılan ilk yerli araştırmalardan biri olarak gösterilebilir. Daha sonraki çalışmalara ise Zeynep Korkmaz, Efrasiyap Gemalmaz, Tuncer Gülensoy, Ahmet B. Ercilasun, Ahmet Buran, Leyla Karahan ve benzeri gibi birçok isim Anadolu ağızları üzerine çalışmalar yapmıştır.

\section{Gözene İsminin Kökeni}

Gözene köyü, Doğu Anadolu bölgesinde bulunan Malatya ilinin en eski köylerinden biridir. Aldı̆̆ isim itibarıyla "derbent” olarak da bilinmektedir. Kubbealtı sözlük anlamı ise; "1) Dar geçit, boğaz; 2) Aşı1ması, alt edilmesi güç durum; 3) Osmanlı Devleti’nde ulaşım bakımından önemli olan dağ geçitlerinde, boğazlarda, yol kavşaklarında kurulan, âsâyiş ve huzûrun sağlanmasında, yolların îmârında büyük rol oynayan karakollara verilen isim" olarak adlandırılmaktadır. Gözene'nin kelime anlamı olarak "pınar, kaynak" anlamlarına gelen "göze" kelimesiyle alakalı olduğu, derleme sözlüğünde ise "göz, göze, gözek ve gözene" sözcüklerinin "suyun çıktığı yer, kaynak" şeklinde ortak bir anlamda birleşmesinden de anlaşılmaktadır. Bununla birlikte derbent köylerinde önemli sulama tesislerinin oluşturulması da bu anlamı destekler niteliktedir (Koç-Dönmez, 2019: 3). Köyün ismine bakıldığında gelişigüzel verilmediği, bulunduğu konum ve yerleşiminden dolayı aldığı da bilinmektedir.

\section{Oyunlarla İlgili Olanlar}

beş T(t-d)aş: Beş taş oyunu geçmişte halk arasında oynanan bir oyun türüdür. Türkçe sözlükte "beş tane taşla oynanan bir çocuk oyunu türü” şeklinde geçmektedir. Kültür noktasında önemli yer edinen oyunlar arasında olan beş taş oyunu, derlemeden edinilen bilgilere göre günümüzde artık oynanmayan ve özlenen bir oyundur. Kitle iletişim araçlarının hayatımızın büyük bir alanını teşkil etmesi sebebiyle eski oyunlar artık unutulmaya yüz tutacak duruma gelmiştir. Gözene köyünde yaşayan orta yetişkin dönemindeki insanlar bu oyunun eskiden çok sık oynandığını ifade etmişlerdir. Beş adet taş ile açık ve kapalı mekânlarda, her mevsimde ve her saat diliminde oynanmaktadır (Özdemir, 2006: 41). Beş taş oyunu, beş adet taşın yere atılmasıyla başlar ve ellerin havaya kaldırılıp indirilmesiyle, yerden taşın alınmasıyla devam eder. Anadolu'nun farklı yörelerinde oynanan bir oyundur. Katı, oyunun oynanış şeklini şöyle ifade etmiştir:

"Oyuna başlama hakkı elde eden oyuncu, avucuna beş taşı alır ve önüne atar. Yerdeki bu beş taşın içerisinden birini alır ve tek eliyle havaya attıktan sonra yine aynı eliyle yerden bir taş alıp aynı anda da havaya attığı diğer taşı yakalamaya çalışır. Havaya tekrar taş atar ve yerdeki taşların hepsini bu şekilde toplar. Daha sonraki aşamada taşları, ikişer ikişer toplar. Sonra havaya attığı taşı düşürmeden yerdeki taşın üçünü birden alır ve diğerini tek alır. Elindeki taşlardan birini havaya atar ve diğer taşları düşürmeden yere koyar. Elindeki taşı tekrar havaya atar ve dört taşı yerden alır. Taşlar avucunda iken taşın birini havaya atar ve "Bal parmak" diyerek işaret parmağını yere değdirir ve taşı tekrar yere düşürmeden yakalar. Oyuncu bütün taşları yere atar. Taşlardan birini eline aldıktan sonra diğer elinin baş ve işaret parmağıyla taşların yakınında köprü pozisyonu alır. Diğer oyunculardan birisi "Bu benim itim." diyerek taşlardan birini sahiplenir. Artık bu taşa değdirilmeden diğer taşlar, köprünün altından, taşın birisi havaya atıldığı esnada sırasıyla geçirilecektir. En son, diğer oyuncunun seçtiği taş geçirilir. Eğer taş, yandan dışarı giderse oyuncu yanmış olur. Bütün taşları kuralına uygun şekilde geçiren oyuncu, taşları iki avucuna alıp havaya atar ve bitiştirdiği ellerinin üst tarafında onları tutmaya çalışır. Sonra tekrar havaya atar ve bu sefer de avuç içiyle tutar. Taşların hepsini tutamazsa yanar. Son olarak oyuncu, taşları tek eline alıp havaya atar ve tek elinin tersiyle tutmaya çalışır. Kaç taş tuttuysa ona göre 
taş başına ikişer puan verilir. Önceden belirlenen sayıya ulaşan oyuncu, oyunu kazanmış olur (Katı, 2020: 320-321).

“şu beş Taş alırdıћ” (Koç-Dönmez, 2019: 60).

Çalgab: Derleme metninden edinilen bilgilere göre Malatya ili Gözene köyünde taşla oynanan bir oyun adıdır. "çalgap" oyunu günümüzde artık oynanmayan eskiden halk arasında oynanan bir oyundur. Terim olarak sözlüklerde de pek rastlayamadığımız bir oyun adıdır. Bu nedenle bu oyun hakkında verebileceğimiz bilgiler çok sınırlıdır.

“Çalgab derdiK Taşınan oynardıћ” (Koç-Dönmez, 2019: 60).

círíd: Cirit oyunu Malatya ilinin Gözene köyünde eski zamanlarda oynanan ve atalarımızın kültürünü temsil eden özel bir oyundur. Kelime köken olarak Arapçaya dayanır. Cirit oyunu Türkçe sözlükte 1 . At koşturup birbirine değnek atarak takım hâlinde oynanan oyun, cirit oyunu, 2. Bu oyunda atılan değnek şeklinde geçmektedir. Cirit oyununun at üzerinde de oynandığını yine derleme metninden öğreniyoruz. Türk kültüründe atın önemi ve kutsallığı göz ardı edilemez. Atın hızlı oluşu, gücü, çevikliği ve asaleti, bozkır uygarlığının tarihi ve kültüründe ona ayrı bir değer kazandırmıştır (Alekseyev, 1981: 149-164). Bozkır hayatının ve göçebe hayat tarzının Türklere kazandırmış olduğu en büyük alışkanlıklardan biridir. Dolayısıyla at üzerinde yapılan spor dalları da bu noktada hep ilgi çekici olmuştur. Her ne kadar avcılık ve okçuluk at olmadan da yapılan spor dalları arasında bulunsa da Türk milleti bu sporları at üzerinde daha rahat ve daha sıklıkla uygulayabiliyorlardı (Caferoğlu 1972: 170). Osmanlı Devleti'nde çok sık oynanan cirit oyunu, aynı zamanda kahramanlığı temsil etmiştir. Dolayısıyla insanlarla bütünleşen kültürel bir oyundur.

“şu an o círíd fálan yoћ ķıSım círíd kalkdı” (Koç-Dönmez, 2019: 60).

ÇıSḳı: "çizgi” oyunu Malatya ili Gözene köyünde var olan bir oyun adı olarak karşımıza çıkmaktadır. Açık alanda tebeşir vb. bir gereç yardımıyla yere çizgi çekilir ve çizginin sınırları çevresinde atlanması şeklinde oynanır. Günümüzde ise çocuklar bu oyunu hâlâ oynamaktadır. Yöresel açıdan birtakım farklılıklar olsa da çocuklardaki oyun kültürü hemen hemen aynıdır diyebiliriz. Günümüzde oyunların dijital bir ortamda oynanması, internet ve sosyal medya gibi sanal mecralarda yaygınlık göstermesi geleneksel oyunların unutulmasına neden olmuştur. Sanal bir dünyanın içine hapsolmuş çocuğun oyun içinde kullandığı malzeme/oyuncak tamamen sanaldır ve paylaşıma kapalıdır (Sümbüllü-Altınışık, 2016: 75).

“Ç1Sķ1 oynardīh” (Koç-Dönmez, 2019: 60).

ķuved Taşı: Malatya ili Gözene köyünde eskiden oynanan bir oyun adıdır. Oyunun derleme metninde sadece taşla oynanan bir oyun olduğu bilgisi yer almaktadır.

“ķuved Taşı dérlerdi” (Koç-Dönmez, 2019: 54).

tura: Malatya ili Gözene köyünde eskiden oynanan bir oyun adı olup günümüzde unutulmuştur. “tura” oyunu Divân-1 Lügâti’t-Türk’te tugrag: "Tugra, tura. Hakanın mührü, buyrultusu. Oğuzca. Bunu Türkler bilmez. Ben de aslını bilmiyorum.” (Divan I,462) şeklinde geçmektedir. Derleme sözlügünnde ise 1. Kimi oyunlarda ebeye vurmak için kullanılan düğümlenmiş mendil. 2. Düğünlerde

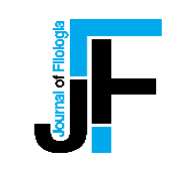


oynanan bir çeşit oyun" şeklinde yer almaktadır (Derleme, 3993-3994). Derleme metnimizde tura oyununda kullanılan bir aracın kişiye temas etmemesi büyük önem taşımaktadır. Buradan hareketle derleme sözlügünde bulunan 2. anlam metnimizdeki oyun türüyle daha çok uyum sağlamaktadır. Anadolu'nun Kırşehir, Alanya, Malatya gibi farklı yörelerinde hâlâ oynanan bir oyun olduğu bilinmektedir. Öztürk, tura oyununun oynanışını şöyle ifade etmiştir:

"Tura, bir takım oyunu olup, en az ikişer kişiden oluşan iki takım arasında oynanır. Çelik oyunu hem erkekler hem de kızlar tarafından ayrı ayrı veya karışık olarak oynanabildiği hâlde tura oyunu sadece kızlar arasında oynanır. Bundan dolayı turayı bir kız oyunu olarak nitelendirmek doğru olur. Oyuncuların belli bir yaş sınırlaması olmamasına karşılık, daha çok gençler arasında oynanır" (Öztürk, 2003: 93).

"sona tura oynallardı böyle şeyi ısladıllar tura oynallardı" (Koç-Dönmez, 2019: 55).

\section{Yemekle ve Gıda İle İlgili Olanlar}

1.cıvıh: "clvık" Gözene yöresine ait olan bir yemek adı. Derlemeden edindiğimiz bilgilere göre nohut, fasulye veya patates gibi ürünlerle yapılan bir yemektir. Sözcük, derleme sözlüğünde "clvıh, clyık, civih, cuvuk, çıvıh” şeklinde geçmektedir (DS. III, 943).

“yahını cıvıћ yapardıћ” (Koç-Dönmez, 2019: 125).

“cıvık” yemeği eski zamanlarda Malatya'nın Gözene köyünde yapılan ancak günümüzde unutulan veyahut pek fazla yapılmayan bir yemek adı olarak karşımıza çıkmaktadır.

2.çerıg: "çerı" Kayısının kesilip doğrandıktan sonraki şekli. Derleme metninden edindiğimiz bilgilere göre kayısı ağaçtan koparıldıktan sonra tane şekline getirilir. Daha sonra kayısı tanelendikten sonra dökülür. $\mathrm{Bu}$ işlemlerin tamamlandıktan sonra kayısı "çerıg" hâline dönüşür. Kayısı Malatya ilimizle özdeşleşen bir meyve olduğu için bu ilimizde kayısı ve onun türevleri ile ilgili pek çok terim bulunmaktadır. "çerı" ifadesi de bu terimlerden biridir.

"géri onu ya çerıg ediyolar tenelerinen teneliyolar” (Koç-Dönmez, 2019: 61).

3.kömbe: "kömbe" Kömbe, hamurdan yapılan böreğe benzeyen bir yiyecek adı. 'İki saç arasında ya da külde pişirilen mayasız ekmek' (Gülensoy, 2007: 552). Gülensoy, hazırlamış olduğu etimolojik sözlükte "kömbe" yemeğinin mayasız ekmek şeklinde hazırlandığını ifade etmişse de derleme metninden Gözene köyünde bu ekmeğin hamuruna maya koyulduğunu öğrenmekteyiz. "kömbe" derleme sözlüğünde "kombe, kömbe, kömpe, könbe, kumpe, kümbe" şeklinde geçmektedir (DS. VIII, 2955). Kömbe, Kahramanmaraş, Osmaniye gibi farklı illerimizde de yapılan bir yemektir. Malatya yöresinde de çok sık yapılmaktadır.

"Kömbe denilince Malatya bölgesinde yapılan ve börek benzeri olan yöresel bir yemek akla gelir. Fakat Malatya Darende ilçesindeki kömbe hamur miktarının fazla oluşu ve dolgu maddelerinden dolayı çok daha farklıdır. Malatya'nın en uzak ve en büyük ilçesi olan Darende yemek kültürü olarak bağlı bulunduğu ilden farklılıklar arz etmektedir” (Yurt, Yıldız, Küçüköner, 2010: 450).

“küfde yaparım kömbe yaparım” (Koç-Dönmez, 2019: 105).

4.tevek: "tevek" Sarması yapılan bir bitki türü. Malatya'nın Gözene köyünde "tevek sarması" yapılır ve bu sarma tevek yaprağından yapılır.'1.Asma, kavun, karpuz gibi bitkilerin sürgünü veya dalı; 2.üzüm kütüğü, çotuk.' (Gülensoy, 2007: 887). “tevek” derleme sözlügü̈nde “teğek, tevek, tefek, tegeg, tegek, tevak, teveklik, tevenk, teyek, teyik, tiyek” biçimlerinde geçmekte olup 1. asma, kavun, karpuz, 
kabak gibi bitkilerin dalları; 2. kavun, karpuz, hıyar vb. bitkilerin dalları; 3.asma yaprağı; 4.üzüm asmasının taze filizi; 5.genç üzüm fidanı; 6.üzüm kütüğü; 7.üzüm salkımı; 8.üzüm bağı; 9.asmanın sarıldığı kuru ağaç; 10.ağaç yaprağı; 11.kış için dal ve yapraklarıyla saklanan soğan, kavun, karpuz vb. sebzeler; 12. yaz kış yeşilliğini koruyan bir tür bitki anlamlarına gelmektedir (DS. X, 3859, 3901).

Tevek, sonuç olarak bir yaprak türü olup sarması yapılan bir bitkidir. Aynı zamanda salamura işlemi de yapılabilen bir bitkidir.

“sarma şey tevek sarması” (Koç-Dönmez, 2019: 77).

5.zarha: "zarha" Zahire. Türkçe sözlükte zahire, gerektiğinde kullanılmak için saklanan tahıl, aşlık şeklinde tanımlanmıştır. Anadolu'da kış mevsiminde yenmesi için yiyecek kaldırılması işlemi Gözene köyünde "zarha" olarak adlandırılıyor. Sonuç olarak gıda ile ilgili söz varlığı alanına girdiği için çalışmamızda bu sözcüğü de ele aldık.

“zarha ķomıya çuvallar doћurduћ” (Koç-Dönmez, 2019: 60).

\section{Mevsimlerle İlgili Olan}

1. zahmarı: i. (Ar. zemherir) 22 Aralık - 31 Ocak arasındaki çok soğuk günler, karakış; zemheri. Ocak aynın öteki adı da zemheridir ve kara kış olarak da bilinir. Anadolu'da halk arasında hava çinko gibi ayaz, kurşun gibi ağır ve nefesi donduran soğuğa zemheri derler. Ocak ayı kışın ortası olarak da bilinir.

Bu Türk takviminde yılbaşı, kova burcunun tam ortasıdır (6 Şubat). Yine bu yılbaşı günü yani Şubat'ın altısı, Kasım ayının sekizinci günü başlayan "Kasım günleri"nin de, Aralık ayının yirmi ikisinde başlayıp "zemheri" ya da "erbain" denen kırk günlük ve onun ardında başlayıp elli gün süren ve Martın yirmi birinde biten "hamsin" ile 90 günlük kış mevsiminin de aşağı yukarı ortasıdır (Çağatay, 1978: 125).

“ḳ1ş günü soūḳ zahmarı günü” 2-163.

\section{Sonuç}

$\mathrm{Bu}$ çalışma Gözene köyünün dil özellikleri esas alınarak oluşturulmuştur. Herhangi bir toplumun bulunduğu konumun ve ikliminin tarih boyunca çeşitli topluluklarla etkileşim içinde olması, konuşulan dil üzerinde de doğal olarak etkili olmuştur. Toplumlar arası dil etkileşimi; ticaret, göç, din ve fetihler sayesinde gerçekleşmektedir. Gözene köyünün tarihsel süreç içerisinde geçirdiği değişimler, hem dili hem de kültürünü doğal olarak etkilemiştir. Ancak bu değişimler çok asgari düzeyde kalmıştır. Köyün bu özelliğinden dolayı dil özellikleri, iyi bir şekilde muhafaza edilmiştir. Teknolojik gelişmeler ise dile yeni kelimeler kazandırmış bunun yanı sıra gelenek-göreneklerin yok olmasına neden olmamıştır. Bu çalışmada Doç. Dr. Özlem Demirel Dönmez ile Dr. Fatma Koç’un birlikte hazırladıkları "Malatya İli Yeşilyurt İlçesi Gözene Köyü Ağzı" adlı kitapta bulunan derleme metinleri kullanılmıştır. Bir yöredeki oyun geleneği o yörenin kültürü üzerinde oldukça etkilidir. Oyunların adlandırılmasında kullanılan ifadeler, dilciler için bir çalışma alanı olup dilimizde unutulmaya yüz tutan sözcükleri yaşatmak adına oldukça önemlidir. Çalışmada derleme metninden edindiğimiz bilgilere göre Gözene köyünde oynanan ve günümüzde unutulan beş Taş, Çalgab, círíd, ÇıSķı, k,uved Taşı, tura olmak üzere 6 adet oyun adı tespit edilmiştir. Gözene köyündeki yemek ve gıda kültürü ile ilgili olan adlandırmalar ise clvıћ, çerıg, kömbe, tevek, zarha olmak üzere 5 adettir. Mevsimle ile ilgili olarak zahmarı sözcüğü kelimesi tespit edilmiştir. İncelenen toplam sözcük sayısı ise 12 'dir. Çalışmanın sayısal verileri aşağıdaki tabloda gösterilmiştir. 


\begin{tabular}{|l|l|}
\hline Konularına Göre Geleneğe Ait Sözcükler & Sözcük Sayısı \\
\hline 1.Oyunlarla İlgili Olanlar & 6 \\
\hline 2.Yemekle ve Gıda İle İlgili Olanlar & 5 \\
\hline 3. Mevsimle İlgili Olan & 1 \\
\hline TOPLAM & 12 \\
\hline
\end{tabular}

$\mathrm{Bu}$ derleme metinleri içerisinde köye özgü olan ve saflığını yitirmemiş kelimeler bir araya getirilerek Gözene köyünün söz varlığı gün yüzüne çıkarılmaya çalışılmıştır. Ağız sözlükleri bir yörenin söz varlığını belirlenmesinde ve kullanılan sözcüklerin nesilden nesile aktarılmasında önemli rol oynar. Kullanılan kelimelerin ihtiva ettikleri mânâ hazinesi dilciler için de büyük bir çalışma alanı oluşturmaktadır. İncelenen sözcükler, Türk dili tarihinin seyri için önemli kaynak olmasının yanı sıra arkeologlar ve sosyologlar için de önemli bilgiler barındırmaktadır. Bu bağlamda bakıldığında Gözene köyünün söz varlığını ile ilgili ele alınan konular "Oyunlarla İlgili Olanlar, Yemekle ve Gıda İle İlgili Olanlar ve Mevsimle İlgili Olan" başlı̆̆ı altında incelemeye çalışılmıştır. İncelenen kelimelerin anlamı verildikten sonra örnek cümleler 1şığında belirtilmeye çalışılmış ve toplamda 12 kelime incelenmiştir. Her yörenin dil özellikleri, birer kültür hazinesi ve dil yadigârı olması açısından çok önemlidir. Ortaya konulan bu derlemeler ağız araştırmaları içerisindeki söz varlığı alanı açısından da mühimdir. Ayrıca hazırladığımız bu çalışma, ağız araştırmaları içerisinde klasikleşen ses ve şekil çalışması olmayıp söz varlığı ile ilgilidir. Ağız araştırmaları içerisinde bu çalışma gibi söz varlığı araştırmalarına ne kadar çok yer verilirse Türk dili sahasında diyalektoloji malzemelerimiz o kadar gün yüzüne çıkar ve bu durum da dilimizin yaşatılmasına yardımcı olur. Yani ağız çalışmaları içerisinde söz varlığı çalışmalarının minimal düzeyde yapılması, yöntem açısından daha sağlıklı sonuçlar ortaya koyacağını göstermektedir. Bu çalışmanın yapılacak olan diğer araştırmalara katkı sağlayacağını ümit ediyoruz.

\section{Kaynakça}

Alekseyev, Vassili. (1981). "Domaşnaya Loşad Mongolii”. Arheologiçeskiye, Etnografiçeskiye i Antropologiçeskiye İssledovaniya v Mongolii. Novosibirsk. Arhceologiya Kazahstana, Almatı.

Caferoglu, Ahmet. (1972). “Türklerde Av Kültürü ve Müessesi”, VII. Türk Tarih Kongresi, Ankara: TTK Yayınları, 170-175.

Çağatay, Neşet. (1978). Eski Cağlardan Bu Yana Zaman Ölçümü Ve Takvim. Ankara Üniversitesi İlâhiyat Fakültesi Dergisi, Cilt: XXII.

Demirel Dönmez, Özlem ve Koç, Fatma. (2019). Malatya İli Yeşilyurt İlçesi Gözene Köyü Ağz1. Ankara: Sonçağ Yayınları.

Derleme. (1993). Türkiye'de Halk Ağzından Derleme Sözlüğü, C.X, 2.bs., Ankara.

Divan. (1986) Divanü Lügati't-Türk, c.I, (Çev: Besim ATALAY), Ankara.

Ergin, Muharrem. (2013). Türk Dil Bilgisi, İstanbul: Bayrak Yayınları.

Gemalmaz, Efrasiyap. (1989). Ağız Bilimi Araştırmaları Üzerine Genellemeler. Türk Kültürü Araştırmaları Halil Fikret Alasya’ya Armagan Ayrı Basım (149.-159. Sayfalar). Ankara: Ankara Üniversitesi Basımevi. 
Gökçe, Hüseyin. (2019). Bursa Dağ Yöresinden (Keles ve Orhaneli İlçelerinden) Derleme Sözlüğüne Katkılar, ed. Hatice Şahin, Bursa: Uludağ Üniversitesi Fen-Edebiyat Fakültesi Dergisi, C.20, S. 36, ss. $79-100$

Gülensoy, Tuncer. (2007). Türkiye Türkçesindeki Türkçe Sözlüklerin Köken Bilgisi Sözlüğü. Ankara: TDK Yayınları.

Kat1, Yasemin, (2020). Malatya Geleneksel Çocuk Oyunları ve Çocuk Gelişiminde Oyunun Rolü, Akra Kültür Sanat ve Edebiyat Dergisi cilt 8 say1. 22, 309-338.

Korkmaz, Zeynep. (1992). Gramer Terimleri Sözlüğü. Ankara: Türk Dil Kurumu Yayınları.

Özdemir, Nebi. (2006). Türk Çocuk Oyunları I-II. Ankara: Akçağ Yayınları.

Öztürk, Rıdvan. (2003). Fiziksel Tanımlama, Milli Folklor, 12 /57, 92-95.

Sümbüllü, Yusuf Ziya ve Altınışık, M. Emin. (2016). Geleneksel Çocuk Oyunlarının Değerler Eğitimi Açısından Önemi, Erzurum Teknik Üniv, Sosyal Bilimler Enstitüsü Dergisi, I/2, Sayfa: 73-85.

Topaloğlu, Ahmet. (1989). Dil Bilgisi Terimleri Sözlüğü, İstanbul: Ötüken Neşriyat A.Ş. Yayınları.

Tuğluk, Mehmet Emin (2021). “İlyas Köyündeki (Diyarbakır-Çüngüş) Tarım ve Hayvancılık ile İlgili Söz Varlığı” Uluslararası Dil, Edebiyat ve Kültür Araştırmaları Dergisi. (UDEKAD). 4 (1): 153-169

Türk, Osman. (2017). Türkçe Öğretmenlerinin Konuşma İlgileri Ve Sınıf İçinde Kullandıkları Konuşma Dili Üzerine Bir Araştırma. Turkish studies, 12(6), 783-798.

Türk, Osman. (2020). Kültürel Miras Olarak Hayvanların Atasözlerimize Kattıkları Anlam Üzerine Bir Değerlendirme. Karadeniz Uluslararası Bilimsel Dergi, 11 (44), (320-334).

Vardar, Berke. (1988). Açıklamalı Dilbilim Terimleri Sözlüğü, İstanbul: ABC Tanıtım Basımevi Yayınları.

Yurt, Bayram ve Yıldız Önder ve Küçüköner Erdoğan. (2010). Malatya Darende Yöresel Yemeği Kömbe, Uluslararası Adriyatikten Kafkaslar'a Geleneksel Gıdalar Sempozyumu Bildiri Kitabı. 